\title{
AS QUESTÕES SOCIAIS, ECONÔMICAS E AMBIENTAIS NA FORMAÇÃO ESCOLAR
}

\author{
Luis Carlos de Menezes
}

Físico e Educador da Universidade de São Paulo

A sociedade contemporânea alcançou tal domínio sobre as forças da natureza, que pode produzir incomparavelmente mais bens e serviços que em qualquer outra era, pode interligar instantaneamente bilhões de pessoas e manipular átomos para conceber materiais inéditos ou informações genéticas para criar novas espécies de interesse produtivo ou médico. Ao mesmo tempo, essa sociedade tem questões abertas, envolvendo desde a estabilidade das nações acossadas pela liberalização global de mercados, dúvidas quanto ao futuro de grande parte do trabalho humano, substituído pela mecanização, pela automação e pela informatização até a ameaça à biosfera como ambiente apropriado à continuidade da vida humana. Na realidade, há mais de um século a tecnologia tem aberto perspectivas notáveis, mas também, como contrapartida, tem trazido ameaças não menos notáveis, algumas já percebidas e denunciadas há muito tempo e freqüentemente reiteradas por quem tem olhado o mundo como objeto de estudo e também de cuidado. ${ }^{1}$

Ao longo do último quarto de século, a fusão de países em blocos, como no mercado Comum Europeu, ou seu fracionamento em guerras étnicas, como na antiga Yugoslávia, o abandono à miséria de enormes contingentes humanos, como na África, e o desequilíbrio socioambiental planetário, são questões mundiais com reflexos ostensivos atuais em crises financeiras, em epidemias alarmantes e em dramas ambientais. Enquanto isso, no plano local, a ameaça da marginalização pelo desemprego estrutural reforça um contexto de competição predatória e fragiliza as instituições que não têm resposta aos desafios contemporâneos. Isso tem resultado em um crescente individualismo e, não raro, em duros conflitos entre grupos e entre indivíduos.

A escola não é uma ilha e recebe de muitas maneiras os reflexos dessas contradições, pois ao mesmo tempo em que dispõe hoje de recursos de informação e

\footnotetext{
${ }^{1}$ Nesse sentido, vale a pena ver com que frases Sigmund Freud e Eric Hobsbawm, com mais de um século de intervalo, terminaram dois livros preciosos, editados no Brasil respectivamente como "O malestar na civilização" - RJ Editora Imago -1997 e "Era dos extremos - o breve sec. 20, 1914 - 1991" São Paulo,Editora Cia. das Letras, 1995 .
} 
comunicação antes impensáveis, também sofre toda a sorte de tensões provocadas pelas inseguranças e problemas individuais e coletivos. Naturalmente, essa condição situa a escola como instituição frágil, exposta a problemas sem precedentes e, em conseqüência, na condição de credora de mais atenção do coletivo ao qual ela serve e de que faz parte. Sem negar essa demanda por uma escola mais preparada e equipada para os desafios que precisa enfrentar, é preciso vê-la como essencial ao enfrentamento dos problemas contemporâneos, mais do que como parte do problema.

Pode-se conceber a escola como cenário dessas discussões por várias razões: primeiro, porque ela é um dos últimos espaços públicos que merecem esse nome, em seguida, porque mais do que qualquer outra instituição, ela seria o espaço para reconstruir o conceito de comunidade, essencial na busca de soluções coletivas e solidárias e, finalmente, porque ela promove o intercâmbio de visões e de culturas, sem o que não se resolvem conflitos. Mas para que a escola possa exercer esses papéis, sem abdicar de sua função de difundir a cultura humana para crianças e jovens, os educadores precisam adotar uma atitude de vanguarda cultural e social de caráter humanista. É essa atitude que lhes permitirá buscar recursos humanos e materiais para promover as transformações necessárias, superando a velha atitude de reivindicação submissa, que não inspira respeito, nem trará resultados.

Essa visão da educação, como âmbito de questionamento e de posicionamento diante de conflitos gerais certamente não é nova, por exemplo, traz ecos do que, no início do século passado, está apontado no trabalho de pensadores socialistas, como Antonio Gramsci, para lembrar um deles. É possível também identificar raízes históricas de proposições de uma escola mais atentamente voltada para as questões do mundo que a abriga, em outras iniciativas de há mais de século, como nas Cooperativas de Educadores Leigos de Célestin Freinet ${ }^{2}$ e em outras iniciativas de caráter exemplar, mas de existência por vezes relativamente efêmera.

Não faltam similaridades também entre esse tipo de posicionamento educacional e as idéias de Paulo Freire, que emergiram de posicionamentos sociais no Brasil dos anos 1950, e tiveram repercussão em muitos outros países antes de voltar a nos alcançar $^{3}$. Mas temos um histórico amplo de linhagens de propostas pedagógicas

\footnotetext{
${ }^{2}$ Para uma introdução ao pensamento de Freinet, veja-se, por exemplo, "Freinet - Evolução histórica e atualidades" S. Paulo, Ed. Scipione, 1994, ou, do próprio Freinet, "As técnicas Freinet da escola moderna", Lisboa, Ed. Estampa, 1975

${ }^{3}$ Pode-se ver o pensamento freiriano em ação na escola pública especialmente nos anos 1980, por exemplo, em “Ousadia no Diálogo”, Nídia Pontuschka (org.) S.Paulo, Ed. Loyola 1993, e para uma
} 
corajosas e engajadas, que é quase constrangedor lembrar como foram interrompidas ${ }^{4}$ mas é preciso atualizá-las, porque há questões novas além das que foram enfrentadas em outras oportunidades, e talvez a relativa diluição do engajamento social e educacional, de algumas décadas para cá, tenha contribuído para que velhas questões tenham se tornado ainda mais graves.

Uma idéia central que anima este pequeno artigo é de que os currículos e os projetos pedagógicos escolares possam, ou mesmo devam, programar uma aprendizagem articulada dos temas sociais, políticos, econômicos e ambientais. Trata-se de sugerir que a vida em sociedade seja observada com uma combinação de múltiplos olhares: a distribuição ou concentração de renda, o maior ou menor acesso aos serviços de educação, saúde, comunicação, cultura, transportes, e às formas de energia utilizadas direta ou indiretamente em cada segmento social, assim como e até especialmente à oportunidade de se obter trabalho, seguridade social ou crédito subsidiado.

Cada um desses aspectos poderia ser examinado por meio da discussão de dados e gráficos oficiais, mas ao se fazer a análise das estatísticas sociais deveria ser também situada a comunidade de cada escola, observada e descrita como tarefa coletiva, ou mesmo analisada a família de cada estudante, como tarefa individual. Se cada um souber se localizar no mapa sócio-econômico, tanto quanto é capaz de achar sua cidade num mapa geográfico, estarão combinados o conhecimento científico e o humanístico com o desenvolvimento de uma consciência social.

As questões sociais, políticas e econômicas na escola básica são hoje tratadas, sobretudo, na história e na geografia humana - e mais recentemente, também na sociologia, quando esta disciplina é ensinada - mas são pouco lembradas nas disciplinas científicas e de linguagens. As questões ambientais aparecem nas aulas de ciências e geografia, mas não chegam a ser objeto de trabalho nas demais. A energia é estudada em física ou química, mas com abordagem formal desacoplada da que se estuda em ciências ou geografia no ensino fundamental e, em geral, sem efetiva associação com a economia.

Aliás, quando na escola se trata de economia, raramente se faz menção à matriz energética, que por si só permitiria um bom diagnóstico do desenvolvimento produtivo

primeira apreciação de sua obra nos reportaríamos ao "Pedagogia do Oprimido", S.Paulo, Ed. Paz e Terra, 2006.

${ }^{4} \mathrm{O}$ nome de Maria Nilde Mascelani não pode ser esquecido em relação aos Ginásios Vocacionais que ela liderou, especialmente nos anos de 1960, e cuja interrupção pode ser associada ao período de exceção, sob o regime militar. 
nacional, da mesma forma que a energia costuma ser esquecida nas aulas de história, mesmo quando ela está nos bastidores de guerras, sobretudo no século 20. Por equívoco semelhante, a problemática ambiental é vista em separado da problemática energética, como se isso fosse de todo possível. De várias maneiras e há mais de uma década, muitos desses aspectos foram apontados, separadamente ou em conjunto, em diversas orientações curriculares nacionais ${ }^{5}$, mas seu reflexo nas salas de aula é ainda extremamente limitado.

Indicadores como o IDH (Índice de Desenvolvimento Humano), assim como conceitos como "desenvolvimento sócio-ambiental sustentável", para poderem abranger o desenvolvimento socioeconômico em sentido amplo, envolvem as fontes e os usos de energia, o acesso a saneamento básico e a serviços de educação e saúde. Por isso são conteúdos de instrução que devem ser trabalhados para promover aquela articulação formativa, especialmente nas disciplinas humanísticas, como geografia e história. O IDH de um município deve ser discutido como a média que é e, especialmente em cidades grandes, pode-se mostrar que as "micro-médias" seriam profundamente diferentes se feitas em um condomínio rico ou em uma favela no bairro ao lado.

Quando se ensinam as disciplinas científicas, como química e física, essas sínteses sociais podem ser mais facilmente incluídas como pontos de chegada, não de partida. Quando em química se discute a ocorrência de jazidas minerais, pode-se revelar seu valor econômico como "commodities", ao lado de sua importância estratégica e política. Quando em física se aprende eletricidade de potência (motores e geradores) e em termodinâmica se aprende a operação de máquinas térmicas (motores a combustão interna) pode-se debater a problemática energético-ambiental, mostrando a matriz energética e o impacto ambiental, ao se estudar a evolução ao longo de décadas do peso relativo das energias renováveis em comparação com os combustíveis fósseis.

As recentes alterações abruptas nos preços da energia e de matérias primas, em função de uma crise econômica de alcance global, dão oportunidade para se discutir aspectos objetivos e subjetivos de preços, ao se tratar a oferta, a demanda e a especulação, assim como, ao se debaterem perspectivas futuras e potencialidades regionais. Nesse sentido da ambientação local dos problemas, cada aspecto econômico, ambiental, energético e social merece uma adequação às condições de vida e trabalho de

\footnotetext{
${ }^{5}$ Ver por exemplo, as Diretrizes Curriculares Nacionais (DCN, Conselho Nacional de Educação, Brasil, MEC 06/1998), assim como os textos da Área de Ciências da Natureza dos Parâmetros Curriculares Nacionais (PCN, MEC, 2002) e de seus textos complementares (PCN+, MEC, 2002)
} 
onde a escola se situa. Contaminação de rio ou desemprego estrutural são realidades que podem ser sentidas e analisadas como vivência próxima, lado a lado com notícias de jornais e TV, gerando-se uma compreensão mais eficaz do que no discurso didático desenraizado ou sem contexto.

Para muitos efeitos, o futuro a médio prazo é imponderável e, por isso, formar a cidadania não é só informar o que se passa, mas também discutir alternativas. Isso só pode ser praticado tratando uma realidade permanentemente cambiante. Por exemplo, as alternativas energéticas dependem da evolução econômica, e talvez adiemos a exploração do caro petróleo do "pré-sal" enquanto perdurar a crise. Da mesma forma, as questões ambientais e econômicas não se separam das sociais e políticas, já que não se pode discutir uma reserva indígena ou um latifúndio improdutivo sem considerar todas essas questões. Isso tudo recomenda uma escola em que conhecimento seja tema vivo de debate não tema inerte de exposição.

Para concluir esse brevíssimo ensaio, vale deixar claro que não se pretendeu, ingenuamente, sobrecarregar as condições reconhecidamente frágeis da escola brasileira, com a responsabilidade de destrinchar todos os graves problemas do mundo e achar solução para as questões sociais, econômicas e ambientais. O que sim se propõe, é fortalecer o caráter de espaço público dessa instituição, dando-lhe maior centralidade e engajamento social, respeitando a inteligência das crianças e jovens ao seu cuidado, no sentido de ganharem maior percepção e consciência do mundo em que crescerão e atuarão, e por meio deles alcançar também suas famílias e sua comunidade. Os exemplos trazidos de passado distante ou recente são, sobretudo, inspiração sobre o que já foi possível fazer, e cuja memória não se deve esmaecer, mas reavivar. 